\title{
A construção dos processos referenciais por alunos do Ensino Fundamental no processo de ensino-aprendizagem de leitura
}

José Alves Ferreira Neto (UECE)*

https://orcid.org/0000-0002-0597-8716

\section{Resumo:}

Este artigo tem como objetivo analisar uma proposta de atividade de leitura, com enfoque no domínio dos processos referenciais. Para a realização deste trabalho, seguimos o pressuposto de que o fenômeno da referenciação é uma atividade sociocognitivo-discursiva de construção de versões do real, propostas pelos sujeitos, mediante o processo de interação. Assim, salientamos que a construção da referência é fundamental para a configuração da coerência textual e, por conseguinte, é de suma importância que os alunos tenham o domínio dos processos referenciais na compreensão dos textos. Intencionamos, portanto, auxiliar os aprendizes no ensino-aprendizagem de leitura, por meio do desenvolvimento das estratégias de referenciação. Como procedimentos metodológicos, produzimos e aplicamos uma atividade de compreensão leitora a alunos de uma turma de 9o ano do Ensino Fundamental, com foco na construção dos processos de referenciação. Promovemos um tratamento qualitativo dos dados analisados. Consideramos que a proposta de atividade pedagógica auxiliou os aprendizes na construção dos sentidos textuais, fazendo com que eles percebessem que os referentes são introduzidos e passam por sucessivas transformações no texto. Para a realização deste estudo, adotamos os postulados teóricos da referenciação, conforme, principalmente, Mondada e Dubois (2003), Cavalcante (2011) e Custódio Filho $(2011 ; 2014)$.

Palavras-chave: Fenômeno da referenciação; Processos referenciais; Ensino de leitura.

\section{Abstract:}

\section{The construction of referential processes by elementary school students in the teaching-learning process of Reading}

* Doutorando em Linguística Aplicada pela Universidade Estadual do Ceará (UECE). Professor efetivo da Secretaria Municipal de Educação de Fortaleza e da Secretaria da Educação do Ceará. Lattes: http://lattes.cnpq.br/0606197492236043. E-mail: jfnetoce@gmail.com 
This article aims to analyze a proposed reading activity, focusing on the domain of referential processes. To carry out this work, we follow the assumption that the referencing phenomenon is a socio-cognitive-discursive activity of building versions of the real, proposed by the subjects, through the process of interaction. Thus, we emphasize that the construction of the reference is fundamental for the configuration of textual coherence and, therefore, it is of paramount importance that students have the mastery of referential processes in understanding the texts. We intend, therefore, to help learners in teaching-learning to read, through the development of referencing strategies. As methodological procedures, we produce and apply a reading comprehension activity to students in a 9th grade class of elementary school, focusing on the construction of referral processes. We promote a qualitative treatment of the analyzed data. We consider that the proposed pedagogical activity helped learners in the construction of textual meanings, making them realize that referents are introduced and undergo successive transformations in the text. To carry out this study, we adopted the theoretical postulates of referencing, as, mainly, Mondada and Dubois (2003), Cavalcante (2011) and Custódio Filho (2011; 2014).

Keywords: Phenomenon of referencing; Referential processes; Reading teaching.

\section{Introdução}

0 processo de referenciação é um dos fenômenos textual-discursivos mais importantes para a construção dos sentidos via textos. Dessa forma, adotamos os postulados sociognitivistas da Linguística Textual (CUSTÓDIO FILHO, 2011), que evidenciam que a construção e reconstrução de referentes é de suma importância para a configuração da coerência textual, o que demonstra a importância de pesquisas sobre essa temática, a fim de se depreender os sentidos construídos durante as interações sociodiscursivas.

Neste artigo, buscamos estabelecer uma relação entre teoria e prática no âmbito da Linguística Textual, a partir dos pressupostos teóricos da referenciação, para o processo de ensino-aprendizagem de leitura. Desse modo, verificamos os resultados obtidos com uma atividade de compreensão leitora que produzimos e aplicamos a alunos de uma turma de 9o ano do Ensino Fundamen- tal, cujo foco é o domínio dos processos de referenciação. Salientamos que a adequada mobilização dos processos referenciais na leitura dos textos é um dos objetivos de ensino-aprendizagem de Língua Portuguesa preconizados pelos Parâmetros Curriculares Nacionais (PCN) (BRASIL, 1998) e pela Base Nacional Comum Curricular (BNCC) (BRASIL, 2018).

Diversos processos, como a continuidade e a progressão textuais e a estrutura dos recursos linguísticos na expressão da relação entre constituintes do texto são essenciais para a configuração dos sentidos dos textos. Entretanto, o trabalho com esse processo textual-discursivo, na educação básica, ainda se restringe, geralmente, à coesão cotextual, conforme constatado por Cavalcante, Custódio Filho e Brito (2014) e Santos e Colamarco (2014). Essa visão limitada sobre a construção da referência não proporciona contribuições significativas para 
o desenvolvimento da compreensão leitora dos alunos.

Assim sendo, faz-se necessário relacionar a proposta teórica da referenciação, sob a perspectiva sociocognitiva, ao processo de ensino-aprendizagem na educação básica, de modo a desenvolver a competência leitora dos aprendizes. Corroboramos, portanto, o posicionamento de Souza (2015), que assevera que o trabalho com o fenômeno da referenciação é fundamental para o êxito do trabalho com textos, na escola, uma vez que, para se apreender os sentidos textuais, é primordial considerar um dos seus expedientes mais relevantes: o ato da construção da referência sobre pessoas, objetos, emoções ou qualquer entidade.

0 artigo se organiza em duas seções: na primeira, falamos sobre a proposta teórica da referenciação e sobre os tipos de processos referenciais; na segunda, demonstramos nossa análise e discutimos os resultados obtidos, além de refletir sobre a pertinência de se aplicar, na prática docente, o que é preconizado pelo arcabouço teórico da Linguística Textual.

\section{Os pressupostos teóricos da referenciação}

A Linguística Textual, sob a perspectiva sociocognitivo-discursiva, tem a proposta teórica da referenciação como um de seus temas fulcrais de investigação. Nesse sentido, Mondada e Dubois (2003) rejeitam a concepção segundo a qual a língua se constituiria como um sistema de etiquetas, como se as palavras representassem objetivamente a realidade. Nesse tocante, as autoras (2003, p. 19) ressaltam que

este ponto de vista pressupõe que um mundo autônomo já discretizado em objetos ou 'entidades' existe independentemente de qualquer sujeito que se refira a ele, e que as representações linguísticas são instruções que devem se ajustar adequadamente a este mundo.

Cavalcante et al. (2017) explicam que a concepção representacional da referência pode ser percebida quando as pessoas acreditam que, por exemplo, um objeto, um sentimento ou uma pessoa são sempre conceituados e apresentados de maneira unívoca, sem que o processo de interação entre os interlocutores impinja a essas entidades especificidades, negociadas e coerentes, de forma a atender a objetivos específicos.

Em oposição a esta concepção, Mondada e Dubois (2003) preconizam a visão segundo a qual os sujeitos constroem versões do real, durante as práticas discursivas. Diante disso, ressalta-se que a língua e a realidade são marcadas por uma instabilidade constitutiva. É nessas práticas discursivas que emergem os referentes, que devem ser tratados como objetos de discurso, ou seja, categorias cognitivo-discursivas, que se constituem como reelaborações da realidade efetuadas pelos interlocutores durante a interação linguística.

No Brasil, pesquisadores como Koch (2017), Cavalcante (2011) e Custódio Filho (2011) têm embasado suas análises a partir dos estudos seminais de Mondada e Dubois (2003). Nesse panorama, Koch (2017) explica que o fenômeno da referenciação se constitui como uma atividade discursiva. Os enunciadores, durante o processo de interação comunicativa, realizam escolhas significativas conforme os seus objetivos pretendidos, sempre orientados pelo princípio da intersubjetividade, isto é, a atividade discursiva pressupõe a interação entre os interlocutores, que agem colaborativamente para a construção de objetos de discurso. Nesse tocante, Koch e Elias (2018, p. 124) Ressaltam que "as formas de referenciação são es- 
colhas do sujeito em interação com outros sujeitos, em função de um querer-dizer".

Assim sendo, no processo de referenciação, tem-se a construção de objetos de discurso, que são entidades discursivas e cognitivas que emergem durante o processo de interação. Cavalcante (2011) explica que os objetos de discurso, normalmente, são homologados na materialidade textual por meio de estruturas linguísticas específicas, chamadas de expressões referenciais. Essas estruturas linguísticas podem ser sintagmas nominais, sintagmas pronominais em função substantiva ou sintagmas adverbiais ${ }^{1}$.

0 dinamismo da proposta da referenciação se ancora em três princípios fundamentais (MONDADA; DUBOIS, 2003; CUSTÓDIO FILHO, 2011; CAVALCANTE, CUSTÓDIO FILHO; BRITO, 2014): 1) a instabilidade do real; 2) a negociação entre os interlocutores; 3) a natureza sociocognitiva da referência.

A respeito desses três princípios fundamentais do processo de referenciação, Santos e Colamarco (2014, p.45) elucidam que

Os objetos de discurso são construídos na prática sociocognitiva, por isso a instabilidade dos referentes é inerente ao discurso, e o processo de construção/reconstrução dos objetos de discurso pressupõe uma interação entre os sujeitos do discurso, responsáveis por escolhas significativas para representar os referentes de acordo com a sua proposta de sentido. Só é possível identificar os objetos de discurso a partir de associações cognitivas, e os processos referenciais colaboram na construção dos efeitos de sentido das escolhas linguísticas no projeto de dizer (grifos nossos).

Como vemos, a construção dos referentes é resultante de uma relação entre os elementos sociais e os aspectos cognitivos,

1 Nos textos em que analisaremos os processos referenciais, mostraremos a ocorrência dos objetos de discurso e das expressões referenciais. de maneira que a natureza instável do real é uma propriedade inerente aos objetos de discurso, a qual se relaciona com a natureza eminentemente intersubjetiva das práticas interativas. Os sentidos textuais se constroem, portanto, na própria situação de interação entre os enunciadores, os quais realizam escolhas discursivas de acordo com aquelas que consideram que sejam as mais pertinentes para a concretização do seu projeto de dizer.

Cavalcante (2011) explica que os processos referenciais se dividem em três grandes categorias: a introdução referencial, que corresponde à apresentação de novos referentes; as anáforas, que correspondem às retomadas de um referente; e a dêixis ${ }^{2}$, que se caracteriza por promover um elo entre cotexto e situação comunicativa. A seguir, apresentamos, em linhas gerais, os processos referenciais de introdução e anáfora, apresentando exemplos dessas estratégias nos textos.

A introdução referencial ocorre quando um objeto de discurso aparece no texto pela primeira vez, sem que nenhum elemento do contexto discursivo ou da situação imediata de comunicação o tenha evocado. Sobre esse recurso, Cavalcante, Custódio Filho e Brito (2014, p. 54) explanam que "a introdução referencial ocorre quando um referente, ou objeto de discurso, 'estreia' no texto de alguma maneira. Isto pode se dar pelo modo mais evidente: por meio do emprego de uma expressão referencial ainda não mencionada anteriormente".

Podemos observar exemplos de introdução referencial no texto a seguir:

Exemplo 1:

O cabo e o soldado

Um cabo e um soldado de serviço dobravam

2 Neste artigo, analisaremos somente os processos de introdução referencial e de anáfora. 
a esquina, quando perceberam que a multidão fechada em círculo observava algo. 0 cabo foi logo verificar do que se tratava.

Não conseguindo ver nada, disse, pedindo passagem:

— Eu sou irmão da vítima.

Todos olharam e logo o deixaram passar.

Quando chegou ao centro da multidão, notou que ali estava um burro que tinha acabado de ser atropelado e, sem graça, gaguejou dizendo ao soldado:

- Ora essa, o parente é seu.

Disponível em: https://www.canaleducacao.tv. Acesso em: 27 jan. 2021.

Neste exemplo, vemos que os referentes "o cabo" e "o soldado" foram introduzidos no texto porque apareceram formalmente no cotexto por meio das expressões referenciais. São analisadas como introduções referenciais, pois não são expressões já "engatilhadas" por nenhuma entidade, atributo ou evento expresso no texto.

As anáforas têm a característica de retomar uma referência, de modo direto ou indireto, consistindo, portanto, na continuidade referencial. Assim sendo, as anáforas são fundamentais para a progressão textual.

Vejamos, a seguir, exemplos de anáforas:

Exemplo 2:

Diabetes sem freio

A respeitada revista médica inglesa "The Lancet" chamou a atenção, em editorial, para o crescimento da epidemia de diabetes no mundo. A estimativa é de que os atuais 246 milhões de adultos portadores da doença se transforme em 380 milhões em 2025. 0 problema é responsável por $6 \%$ do total de mortes no mundo, sendo $50 \%$ devido a problemas cardíacos - doença associada à diabetes.

[...]

Disponível em: https://e-conhecimento.br. com. Acesso em: 27 jan. 2021.
No exemplo em tela, vemos que o objeto de discurso "diabetes", o qual é introduzido por meio da expressão referencial "diabetes sem freio" no título do texto, é retomado por meio das expressões sublinhadas. São casos, portanto, de anáforas, uma vez que está sendo retomado o referente. Ressaltamos que as anáforas desempenham um papel vital na construção do projeto de dizer do produtor textual.

É essencial verificarmos que os referentes retomados, normalmente, vão se transformando dentro do texto. Essa estratégia consiste na recategorização do objeto de discurso, ao qual vão sendo acrescentadas novas informações. Toda essa evolução é essencial para a progressão das ideias do texto, construindo o projeto de dizer do enunciador.

Sobre essa estratégia, Cavalcante, Custódio Filho e Brito (2014, p. 63) esclarecem que

a tendência dos referentes retomados, nas anáforas, é evoluir durante o desenvolvimento do texto. Assim, o referente pode permanecer o mesmo nas anáforas correferenciais, mas, com o acréscimo de informações, sentimentos, opiniões, esperável na progressão das ideias do texto, ele se transforma, isto é, vai sendo recategorizado, tanto pelo locutor quanto pelo interlocutor.

As anáforas recategorizadoras consistem, portanto, nas transformações pelas quais os referentes passam durante a continuidade e progressão referencial. Verificamos, pois, que a recategorização é um recurso fundamental que o enunciador utiliza, continuamente, na produção de seus textos.

Vejamos, a seguir, um exemplo do processo de recategorização.

Exemplo 3:

Computador vence humano em Go, jogo mais complexo que xadrez 
O jogo era um dos poucos que permanecia dominado por humanos

Um computador, enfim, bateu um humano em Go, jogo chinês conhecido por ser um dos mais complexos do mundo. A ideia é simples: peças são colocadas sobre os pontos formados no tabuleiro, se você cerca uma ou mais pedras adversárias, elas se tornam suas. Nenhuma peça se mexe, apenas novas são adicionadas. 0 ponto é que a grande quantidade de casas no tabuleiro aumenta muito as possibilidades de estratégias do jogo - uma partida pode ter mais resultados do que a quantidade de átomos estimados no universo -, o que torna quase impossível um computador calcular as melhores jogadas. Ou melhor, tornava. O Google acredita que esse desafio vai ficar no passado. A empresa afirma ter inventado uma máquina que é praticamente imbatível no jogo.

\section{$[\cdots]$}

Texto de Felipe Germano. Disponível em: <http://super.abril.com.br/tecnologia/ computador-vence-Humano-em GO-jogo -mais-complexo-que-xadrez>. Acesso em: 10 jan. 2021.

No exemplo em tela, vemos que o objeto de discurso "o jogo Go", o qual é introduzido por meio da expressão referencial “Go" no título do texto, passa por variadas recategorizações, como ocorre com as expressões referenciais "jogo mais complexo que xadrez" e "jogo chinês conhecido por ser um dos mais complexos do mundo", que são fundamentais na construção dos sentidos do texto. Assim, essas transformações desempenham um papel vital no projeto de dizer do locutor, mantendo os objetos de discurso e fazendo-os progredir na construção textual.

Nesse panorama, Cavalcante e Brito (2016) esclarecem que os objetos de discurso realizam um trajeto no texto que vai desde os modos como o enunciador decide introduzi-los até as variadas maneiras pelas quais vai conduzindo o coenunciador sobre como espera que ele os interprete (apesar de não poder se assegurar que essas ações decorram consoante as expectativas de cada participante). Assim sendo, os processos de introdução referencial e de anáfora se configuram como estratégias sociocognitivo-discursivas de estabilização de referentes no texto.

Como vemos, no cerne de análise dos processos referenciais, estão as expressões referenciais. Entretanto, concordamos com Cavalcante (2011) e Custódio Filho (2011; 2014) que, além das expressões referenciais, há outras pistas contextuais que auxiliam na construção dos processos referenciais. Ou seja, uma análise da construção referencial não pode ficar restrita a verificar que expressões introduzem e retomam um referente no discurso. Os autores defendem, portanto, que a construção da referência é mais global do que pontual e, por isso, não pode ficar circunscrita à análise de determinados recursos lexicais, quais sejam, as expressões referenciais. Assim sendo, Custódio Filho (2011, p. 167) elucida que essa proposta de abordagem da construção da referência investe "na natureza sociocognitiva do fenômeno para abrir mão de amarras formais que o limitem excessivamente".

Nesse sentido, Custódio Filho (2014) frisa que, no que concerne aos elementos da superfície textual, além das expressões referenciais, temos os sintagmas adjetivais e as predicações como pistas contextuais que colaboram na construção da recategorização, promovendo acréscimos e confirmações de informações aos objetos de discurso.

Além disso, Custódio Filho (2014) divide, em sua análise, as expressões referenciais em dois grupos: aquelas que incidem sobre o referente em análise e aquelas que incidem sobre objetos de discurso diferentes do referente em análise. 0 autor explica 
que, em muitos casos, a construção de um referente central não depende, exclusivamente, das expressões utilizadas para (re) categorizar tal referente; outras expressões, que designam referentes mais periféricos, também podem interferir na compreensão sobre um referente central.

A fim de compreendermos como outras pistas linguísticas podem colaborar na construção referencial, vejamos o exemplo a seguir, analisado em xxxxxxx (2018):

Exemplo 4:

\section{A hóspede}

Era uma tarde quente, Ana, uma moça jovem e feliz, estava esperando Alice, sua amiga de infância que não via há mais de dez anos e que iria voltar de viagem naquele dia. Ela estava esperando-a numa praça pública, quase deserta, havia algumas pessoas conversando. Alguns minutos depois, Ana começou a olhar ao redor e percebeu que não havia mais ninguém na praça.

- Onde será que Alice se meteu? - Ana se perguntou com preocupação.

Ela olhou ao redor novamente e avistou uma moça de cabelos claros, alta e bonita andando vagarosamente.

- [(1) Aquela moça está me assustando.] Acho que vou embora. - Pensou Ana já se levantando, porém ela olhou bem a moça novamente e sentiu que a conhecia.

A garota se aproximou e falou.

- Olá, Ana! [(2) Não está me reconhecendo?] Nossa, magoou! Sou eu, a Alice. - [(3) Ela deu um abraço bem apertado em Ana.]

- Não acredito! [(4) Como você mudou], [(5) estava assustada pensando que era outra pessoa.] - Ana gaguejou de tanta felicidade.

- Tudo bem, então, vamos para sua casa! Alice, que aparentava estar feliz, porém ansiosa, falou.

- Vamos, então! Você está muito linda.

[...]
No título do texto, ocorre a introdução do objeto de discurso "Alice". A personagem é apresentada através da expressão referencial "a hóspede", o que sugere que ela vai se acomodar em algum lugar que não é a sua casa. Com a leitura do texto, sabemos que ela vai ficar hospedada na casa de sua amiga Ana. Já no primeiro parágrafo, o referente sofre a primeira recategorização através de uma expressão referencial: ela e Ana são amigas de infância que vão se reencontrar, após passarem vários anos sem se ver.

Em seguida, ocorrem outras recategorizações a respeito do referente "Alice". A expressão referencial "uma moça de cabelos claros, alta e bonita" a descreve fisicamente. Até aqui, a construção do objeto de discurso se concentrou nas expressões referenciais, entretanto, a partir desse momento, outras pistas linguísticas passam a colaborar para a construção da referência. As construções 1, 2, 4 e 5 e a expressão referencial "outra pessoa" mostram que a moça está diferente fisicamente, por isso causa susto em sua amiga, uma vez que não a reconhece.

Destacamos, em seguida, o termo "um abraço bem apertado" como expressão referencial que incide sobre um objeto de discurso diferente do referente escolhido, pois avaliamos que esse referente auxilia na construção da personagem Alice como uma amiga afetuosa, que está com bastante saudade de Ana. Em uma perspectiva mais ampla, devemos assumir, conforme explica Custódio Filho (2014), que um determinado referente contribui para a construção do sentido de outro referente, de forma que um pode depender do outro, formando uma rede referencial.

Em seguida, ocorrem outras recategorizações através da oração adjetiva explicativa "que aparentava estar feliz, porém ansio- 
sa" para caracterizar o estado emocional da personagem e do sintagma adjetival "muito linda", para demonstrar a forma com a qual a sua amiga a caracteriza.

Observamos, assim, a produtividade das construções linguísticas para a configuração do referente. Os traços de sentidos recategorizados à personagem são resultado da "participação" das diferentes estruturas linguístico-discursivas no processo de construção de sentidos. Não se trata, portanto, somente de identificar as expressões referenciais existentes nas construções. Avaliamos, como Custódio Filho (2014), que seja fundamental averiguar o sentido completo da informação para determinar os traços referenciais para a construção do processo de recategorização.

Na próxima seção, apresentamos a nossa análise e discutimos os resultados obtidos.

\section{Análise dos processos referenciais acionados por alunos de 90 ano do Ensino Fundamental em uma atividade de leitura}

A pesquisa desenvolvida neste artigo se insere no âmbito da Linguística Textual. Reiteramos que o nosso objetivo foi propiciar o desenvolvimento da habilidade leitora dos aprendizes de uma turma de 9o ano do Ensino Fundamental, por meio do domínio dos processos referenciais.

Como procedimentos metodológicos, produzimos e aplicamos uma atividade de compreensão leitora a dezoito alunos de uma turma de 9o ano do Ensino Fundamental de uma escola pública municipal de Fortaleza-CE, com foco na construção dos processos de referenciação. 0 corpus analisado é constituído, portanto, da atividade produzida e das respostas dos aprendizes aos questionamentos propostos. Promove- mos um tratamento qualitativo dos dados analisados.

A carga horária para a realização da atividade foi de 4 horas-aula. Antes de aplicarmos essa atividade, realizamos um momento de "familiarização" com os elementos e as características da sequência narrativa e dos textos do gênero conto, a fim de os estudantes perceberem, sobretudo, como se dá a construção dos personagens nos textos narrativos.

A atividade foi produzida tomando por base o conto "Morto-boys", de Richard Diegues. Com essa atividade, pretendemos fazer com que os alunos percebessem que os referentes são introduzidos e, em seguida, passam por sucessivas recategorizações no decorrer do texto, por meio de várias pistas linguísticas.

A seguir, apresentamos a versão integral da atividade; posteriormente, realizamos a análise e discussão dos resultados.

\section{ATIVIDADE DE INTERPRETAÇÃO TEXTUAL}

1) Leia o texto a seguir e complete as lacunas numeradas de acordo com os itens que você julgar mais adequados. (obs.: os itens estão após o texto).

\section{Morto-boys (adaptado)}

\section{Richard Diegues}

Dois copos com café sobre o balcão. Ao lado do primeiro, o capacete vermelho de Pedro, quase tão surrado quanto a fórmica onde estava apoiado. Ao lado do outro, o de Milton.

Depois de provar o café, Pedro jogou mais três colheres de açúcar nele. Milton adicionou quatro. Bem cheias. (1.1)

- Ontem foi o Xandi. 0 quinto agora. Porra, justo o Xandi, o mais cuidadoso da turma. E foi feio. Parou quase toda a Vinte e Três. 
$-(1.2)$ - perguntou Milton, arrependendo-se em seguida.

- Não, de jeito nenhum. O Chico me avisou pelo celular. Hoje, se vejo sinal de congestionamento, me mando, entro na primeira quebrada. Nem pego mais via principal. Tenho fugido dos carros. Demoro mais pra fazer as entregas, faturo menos, mas...

Um outro capacete foi batido contra o balcão. Edmundo sentou na banqueta livre, ao lado da dupla. Barba rala, rosto farto. Olheiras fartas, olhos ralos.

- É do Xandi que vocês aí tão falando? perguntou, gesticulando ao balconista que trouxesse café com leite e um pão na chapa. - Disseram que foi na Vinte e Três, lá perto do túnel. Foi feio pelo jeito.

Os dois balançaram a cabeça afirmativamente. 0 café e o pão chegaram pela frente. Chico chegou por trás.

- Eu passei pela Vinte e Três ontem, assim que fiquei sabendo. - Tava em serviço de rua. Quase me borrei, mas passei por lá - disse, entrando na conversa, sentando em outra banqueta. - Quando cheguei já tinham levado. Só tinha a moto arregaçada. (1.3) . Graças a Deus. Eu não queria ver. Só precisava confirmar. Foi o quinto, perceberam?

Os quatro permaneceram sentados. Lado a lado. Calados. Comida intocada no balcão. (1.4)

- O Nego foi no Viaduto do Chá. Porra, foi bem na hora da muvuca. Seis da tarde. Gente pra cacete e ninguém viu nada. Como pode? - resmungou Pedro, em desabafo.

- Um camelô disse que viu um carro preto. Com uma loira no volante.

Silêncio.

Edmundo deu um safanão na nuca de Milton.

- Para com isso! Daqui a pouco vai dizer que também tá sendo seguido por aí - gritou Edmundo, conferindo se alguém os observava, além do balconista.
O silêncio seguiu gelado. Passou um bom tempo, (1.5)

— E tô vendo mesmo! Vi um carro lá na Dom Pedro, ontem à noite, quando tava voltando pra casa. Vinha na faixa contrária. E não vem com esse papo de que é só parecido! (1.6) _

- Eu também vi - disse Chico, exaltado.

- Duas vezes. Uma na Brigadeiro. Outra na Paulista. Imagina, bem na Paulista. E o Pedro também já viu — acusou, apontando o colega.

- Eu não tenho certeza se vi - Pedro esquivou-se - Eu ia saindo de casa. Foi anteontem. Vinha aqui pro boteco, como todo dia, pra fazer hora antes de ir pro trampo. Tirei a moto da garagem e olhei pra esquina. Nova neura minha. (1.7)

_. Num dava pra ver bem, mas nem arrisquei. Entrei novamente e liguei pro trampo. Disse que tava doente.

Os três ficaram encarando Edmundo, que remexia nervoso na viseira do seu capacete.

- Tá certo! Também vi a piranha. Vi na Vergueiro, na Juscelino, na Bandeirantes, na Avenida do Estado. Ela quase me acertou, lá na São João... eu tô vendo a vaca toda hora! — falou alto, histérico.

Nenhum dos quatro olhava para o outro. Cada um fitava um ponto diferente do balcão ensebado. Chico rompeu o silêncio dessa vez.

- Quase oito horas. Tenho que ir trabalhar - disse, pegando seu capacete, enquanto levantava e olhava para o balconista. - Pedrinho, põe na minha conta.

Os demais também se levantaram. Saíram do bar e ficaram olhando para as motos recostadas na guia. Ajeitavam as mochilas sem pressa. Colocavam os capacetes sem vontade. Por fim, subiram nas motocicletas e deram partida. (1.8) Estava frio. Suavam mesmo assim.

- Hoje é sexta. A gente podia marcar outro churrasco amanhã... lá na represa - gritou Pedro, tentando suplantar o barulho dos motores. 
-É, a gente podia ir lá novamente. Podia levar equipamento de mergulho. Todo mundo faz isso por lá - respondeu Chico, olhando para os demais.

— Eu levo! - falou Edmundo, sem ânimo. - A gente faz um pouco de mergulho. Todo mundo faz. E se achar alguma coisa estranha... não tô dizendo que vamos achar... a gente chama a polícia. (1.9)

A gente explica que tava se divertindo e, caso ache algo como... um carro preto, na água, diz que foi só coincidência. Essas coisa não têm pista.

— Eles vão sacar. Os cara são esperto.

- Se. Eu disse se, tiver algum corpo lá, dentro de um carro, já tem mais de dez dias. Deve tá podre, saca? E ninguém esqueceu nada lá né? Alguma coisa que possa incriminar certo? Então... Isso é, tipo alguma prova que tenha ficado por lá. E se tiver acontecido algo, é só suposição, entenderam? Suposição! Tudo se resolve... acho que se essa tal loira existisse, só tá querendo sossego.

- Um enterro decente. Isso deve bastar. Não acham?

Todos concordaram com um gesto de cabeça. Precisavam acreditar. Um a um foram partindo. Eram quatro. Os que ainda restavam da turma. Seguiram seu caminho, esforçando-se para conseguirem chegar ao dia seguinte. Todos atentos ao trânsito. Cada um remoendo sua culpa.

\section{(1.1)}

(a) Tudo estava amargo de repente.

(b) Tudo estava mais animado de repente.

(c) Tudo começou a melhorar.

(d) Tudo estava caminhando como o planejado.

\section{(1.2)}

(a) Você estava com ele na hora?

(b) Cê sabe como foi?

(c) Você já sabe quem foi?

(d) Cê viu o corpo?

\section{(1.3)}

(a) E várias pessoas ao redor.

(b) E o sangue no chão.

(c) E muita tristeza no lugar.

(d) E as marcas de freio no chão.

\section{(1.4)}

(a) Cada um com saudades dos amigos.

(b) Nenhum estava gostando da comida.

(c) Cada um mastigando apenas pensamentos.

(d) Nenhum entendia o motivo das tragédias com seus amigos.

\section{(1.5)}

(a) até Milton começar a gargalhar.

(b) até ser quebrado pelos soluços de Milton.

(c) até o balconista entrar na conversa.

(d) até Chico começar a desabafar.

\section{(1.6)}

(a) Os policiais estavam me observando.

(b) Estou ficando cada vez mais com medo.

(c) Vou ter que tomar alguma providência.

(d) A loira tava lá, me olhando com cara de ódio.

(1.7)

(a) E tinha uma loira na calçada.

(b) E tinha uma viatura lá parada.

(c) E tinha um carro preto parado lá.

(d) De repente vi um vulto dentro dum carro.

(1.8)

(a) Todos olharam várias vezes para as duas esquinas.

(b) Todos estavam muito nervosos.

(c) Todos estavam mais calmos.

(d) Todos saíram apressadamente.

\section{(1.9)}

(a) Eles vão investigar tudo direitinho. 
(b) Os home resolve tudo, sem erro.

(c) Os home não percebem nada.

(d) Eles vão acreditar na nossa versão.
2. Complete o quadro a seguir, com as características de apresentação dos quatro amigos: Pedro, Milton, Edmundo e Chico, que aparecem na parte inicial do conto.

\begin{tabular}{|l|l|}
\hline Característica(s) & Trecho(s) confirmador(es) \\
\hline & \\
& \\
& \\
\hline
\end{tabular}

3. Complete os quadros a seguir, com duas características dos quatro amigos, anterio- res à radical transformação pela qual eles passam, que você julgou mais importantes.

\begin{tabular}{|l|l|}
\hline Característica 1 & Trecho(s) confirmador(es) \\
\hline & \\
& \\
& \\
\hline
\end{tabular}

\begin{tabular}{|l|l|}
\hline Característica 2 & Trecho(s) confirmador(es) \\
\hline & \\
& \\
& \\
\hline
\end{tabular}

4. Complete o quadro a seguir, com as características de apresentação da personagem
"Loira", que aparecem na parte inicial do conto.

\begin{tabular}{|l|l|}
\hline Característica(s) & Trecho(s) confirmador(es) \\
\hline & \\
& \\
& \\
\hline
\end{tabular}


5. Complete os quadros a seguir, com duas características da personagem "Loira", ante- riores à radical transformação pela qual ela passa, que você julgou mais importantes.

\begin{tabular}{|l|l|}
\hline Característica 1 & Trecho(s) confirmador(es) \\
\hline & \\
& \\
& \\
\hline
\end{tabular}

\begin{tabular}{|l|l|}
\hline Característica 2 & Trecho(s) confirmador(es) \\
\hline & \\
& \\
& \\
\hline
\end{tabular}

6. Indique a característica que revela uma radical transformação pela qual os quatro ami- gos passam. Indique o trecho do texto em que essa transformação passa a ser percebida.

\begin{tabular}{|l|l|}
\hline Grande transformação dos amigos & Trecho(s) confirmador(es) \\
\hline & \\
& \\
& \\
\hline
\end{tabular}

7. Indique a característica que revela uma radical transformação pela qual a persona- gem "Loira" passa. Justifique com trechos do texto.

\begin{tabular}{|c|c|}
\hline $\begin{array}{c}\text { Grande transformação da } \\
\text { personagem "Loira" }\end{array}$ & Trecho(s) confirmador(es) \\
\hline & \\
\hline & \\
\hline
\end{tabular}


Os alunos, nessa atividade, obtiveram um bom aproveitamento, o que demonstra a pertinência da atividade elaborada para promover a reflexão dos discentes sobre a construção da referência por meio das várias pistas linguísticas.

Para a realização da primeira questão, foram retirados alguns fragmentos do texto, a fim de que os alunos percebessem que a falta de determinados excertos textuais prejudica a continuidade e a progressão textuais. Para cada fragmento retirado, além do enunciado correto, foram criadas mais três opões, a fim de que os alunos escolhessem aquela que considerassem a mais adequada na construção da narrativa. É importante esclarecer que mais de uma alternativa poderia estabelecer sentido na construção do texto, por isso o objetivo principal dessa questão foi promover o debate oral entre os alunos sobre quais alternativas eles julgavam as mais adequadas. Depois da discussão, apresentamos o texto com os fragmentos que haviam sido retirados, para que os discentes conferissem as suas respostas. Essa questão foi bastante interessante, pois proporcionou que os alunos discutissem entre eles como fariam a construção da narrativa, a partir das lacunas que compunham o texto.

Embora a turma tenha apresentado um bom desempenho na atividade proposta, como já foi destacado, alguns alunos realizaram algumas inadequações a respeito do preenchimento dos quadros de apresentação (que corresponde à introdução referencial) e os de acréscimos (que corresponde à recategorização) dos referentes. Por exemplo, o aluno 12 caracterizou a personagem "Loira" como misteriosa e má tanto na apresentação quanto nos acréscimos. Já o aluno 3 caracterizou os personagens dos quatro amigos como medrosos tanto na apresen- tação quanto nos acréscimos. Ou seja, esses alunos confundiram o processo de introdução referencial com a recategorização.

Além da inadequação abordada acima, dois alunos colocaram características que não condizem com a recategorização dos referentes "quatro amigos" e do referente "Loira". Vejamos, a seguir, as respostas apresentadas por esses alunos:

Exemplo 5:

Característica: Pedro, Milton, Chico e Edmundo pareciam estar tranquilos mesmo com esse fato que estava acontecendo; trecho confirmador: "Hoje é sexta. A gente podia marcar outro churrasco amanhã... lá na represa" (aluno 7).

Exemplo 6:

Característica: Uma moça sem importância; trecho confirmador: "A loira tava lá, me olhando com cara de ódio. (aluno 2).

Percebemos, nas respostas acima, que o aluno 7 não compreendeu que o plano dos quatro amigos de fazerem um churrasco na represa era para poder ir atrás do corpo da "Loira", que eles haviam assassinado, e não para sair a fim de se divertirem. Já o aluno 2 colocou uma característica que não se constrói no desenvolvimento da narrativa nem pode ser comprovada pelo trecho utilizado, uma vez que o fragmento que o aluno escolheu mostra que a loira estava causando cada vez mais medo nos amigos, o que comprova o seu papel fundamental na narrativa, diferentemente de ser uma moça sem importância.

No que diz respeito à construção referencial dos quatro amigos, a maioria dos alunos caracterizaram, adequadamente, esses referentes como motoboys medrosos e nervosos no processo de introdução referencial. Podemos observar isso na resposta a seguir, que aparece, na segunda questão, que trata da introdução referencial: 


\section{Exemplo 7:}

Característica: São motoboys que pareciam medrosos e nervosos; trechos confirmadores: "Depois de provar o café, Pedro jogou mais três colheres de açúcar nele. Milton adicionou quatro bem cheias" e "Graças a Deus. Eu não queria ver" (aluno 5).

Na terceira questão, que trata da recategorização dos referentes "quatro amigos", as características mais realçadas apropriadamente pelos alunos, além das duas citadas acima, são o fato de eles estarem assustados. Vejamos isso na resposta a seguir:

Exemplo 8:

Característica: Quando saíram do bar, os amigos pareciam estar assustados olhando para os lados; trecho confirmador: "Saíram do bar e ficaram olhando para as motos recostadas na guia. Todos estavam muito nervosos" (aluno 11).

$\mathrm{Na}$ quarta questão, que trata da introdução do referente "Loira”, as respostas dos alunos destacaram, corretamente, sobretudo, ou o fato de ela sempre aparecer em um carro preto perseguindo os amigos, ou o fato de ela ser a assassina dos amigos dos motoboys. Pode ser observado isso nas respostas a seguir:

Exemplo 9:

Característica: Uma loira assassina; trecho confirmador: "Ontem foi o Xandi. O quinto agora” (aluno 7).

Exemplo 10:

Característica: A loira estava sempre dentro de um carro preto depois dos acontecimentos; trecho confirmador: "Um camelô disse que viu um carro preto. Com uma loira no volante" (aluno 14).

Na quinta questão, que trata da recategorização do referente "Loira", os traços mais destacados apropriadamente nas respostas dos discentes foram que ela é perseguidora e misteriosa. Observa-se isso nas respostas a seguir:

\section{Exemplo 11:}

Característica: Uma mulher perseguidora; trecho confirmador: "E tô vendo mesmo! Vi um carro lá na Dom Pedro, ontem à noite, quando tava voltando pra casa" (aluno 5).

\section{Exemplo 12:}

Característica: Ela era misteriosa; trechos confirmadores: "E tô vendo mesmo!", "Eu também", "Eu não tenho certeza se vi" e "Tá certo, também vi a piranha" (aluno 6).

Na sexta questão, que demanda que os alunos percebam que os quatro amigos passam por uma transformação (recategorização) - de homens perseguidos por uma mulher misteriosa para assassinos da "Loira" -, dois alunos não conseguiram compreender bem essa transformação. Todos os demais alunos perceberam a recategorização pela qual passam os referentes. Observemos, então, as respostas a seguir:

\section{Exemplo 13:}

Grande transformação dos amigos: Eles começaram a inventar várias histórias sobre a loira, perguntando se não tinha nada para incriminá-los; trecho confirmador: "A gente explica que tava se divertindo e, caso ache algo como... um carro preto, na água, diz que foi só coincidência. Essas coisas não têm pista" (aluno 3).

Exemplo 14:

Grande transformação dos amigos: Eles mataram a loira, por isso ela estava atrás deles perseguindo-os; trecho confirmador: "Se tiver algum corpo lá, dentro de um carro, já tem mais de dez dias" (aluno 1).

Conforme podemos observar, o aluno 3 não conseguiu entender, completamente, a real transformação que os referentes "quatro amigos" sofrem, pois, embora ele tenha usado o termo incriminação, ele não se refere, diretamente, ao fato de os amigos serem assassinos, diferentemente do aluno 1 , 
que comprova sua resposta com um trecho muito importante para que se confirme que essa recategorização ocorre.

Apesar de dois alunos não terem percebido a transformação pela qual os quatro amigos passam, todos os alunos perceberam a transformação (recategorização) pela qual o referente "Loira" passa, que é o que se solicita na sétima questão. Vejamos, a título de ilustração, a resposta a seguir:

Exemplo 15:

Grande transformação da personagem "Loira”: A loira é um espírito, pois ela está morta no fundo de uma represa, onde os amigos pretendem ir para fazer um churrasco para encontrar o carro e o corpo dela; trecho confirmador: "Acho que se essa tal loira existisse, só tá querendo sossego, um enterro decente. Isso deve bastar. Não acham?" (aluno 11).

Embora tenham ocorrido algumas respostas não satisfatórias, julgamos que o desvelamento da construção referencial proporcionou uma reflexão proveitosa e necessária aos alunos. As questões possibilitaram que os discentes compreendessem como a construção dos processos referenciais faz com que os referentes progridam no decurso da compreensão textual, por meio da introdução e das sucessivas recategorizações, que alteram o seu estatuto inicial.

Nas respostas analisadas, pudemos constatar que os leitores compreenderam os traços referenciais dos objetos de discurso por meio das várias pistas linguísticas que agem na construção dos sentidos. Ressaltamos, portanto, conforme assevera Custódio Filho (2014), que não só as expressões referencias, mas também as outras pistas cotextuais, como os adjetivos e as predicações, permitem que o leitor, a partir de um trabalho sociocognitivo de negociação com o texto e o produtor textual, construa uma imagem para os referentes. Dessa forma, comprovamos que a referenciação é um processo complexo, que se efetiva, de fato, a partir da conjunção dos vários elementos textuais.

Com essa atividade, pudemos constatar que os alunos apresentaram um domínio maior sobre as estratégias de referenciação, reconhecendo que os objetos de discurso, ao longo da rede referencial, podem se manter e progredir através de diferentes construções textuais. Com isso, ressaltamos que a escola deve proporcionar aos estudantes o domínio das estratégias de referenciação, uma vez que mobilizar tais estratégias é essencial para o desenvolvimento da competência discursiva dos aprendizes.

Percebemos, desse modo, que a atividade aplicada possibilitou que os estudantes agissem como construtores de sentidos, interagindo com o texto, mediante um trabalho de negociação com o produtor textual. Assim, verificamos, como explicam Koch e Elias (2018) sobre o papel do leitor ao interagir com o texto, que os aprendizes buscaram construir os sentidos com base no modo como o texto está constituído linguisticamente, nas sinalizações oferecidas pelo produtor textual, assim como na mobilização do contexto significativo à interpretação.

Nesse sentido, consideramos que a atividade pedagógica alcançou seu objetivo de fazer o leitor interagir efetivamente com o texto para a construção da coerência. Assim sendo, intencionamos que os alunos não tivessem uma atitude passiva na interação com o texto, centrando-se, basicamente, em tentar compreender as intenções do autor. Pelo contrário, verificamos que esta atividade, que tem como foco a construção de sentidos pelo interlocutor, suscitou-os a agir para promover esses sentidos. Uma comprovação disso foi o fato de os alunos terem podido, a partir de sua percepção de leitor, 
modificar a configuração original do texto e discutir com os colegas as opções que eles julgavam serem as mais pertinentes, o que foi essencial para eles se sentirem sujeitos ativos na construção dos sentidos textuais.

Salientamos, portanto, que a aprendizagem de leitura deve possibilitar que o aluno construa os sentidos a partir da interação que estabelece com o texto. Não se pode admitir, assim, a ideia de que os leitores devem apenas captar as intenções do autor do texto, visto que diferentes sentidos podem emergir durante o processo de interação autor-texto-leitor. À vista disso, enfatizamos que, no processo de aprendizagem de leitura, o aluno deve se empenhar em um processo ativo de construção de sentidos, e não, simplesmente, de reconhecimento de intenções do autor.

Diante disso, asseveramos que os postulados preconizados pelo arcabouço teórico da referenciação podem desempenhar um papel importante no processo de ensino -aprendizagem de leitura na educação básica, visto que propicia um processo interativo que prioriza a ação sociocognitiva dos interlocutores (CAVALCANTE, 2011; CAVALCANTE; CUSTÓDIO FILHO; BRITO, 2014).

\section{Considerações finais}

Neste artigo, pretendemos demonstrar uma proposta de atividade de leitura que produzimos e aplicamos a estudantes de 9o ano do Ensino Fundamental de uma escola pública municipal de Fortaleza-CE, cujo foco foi o domínio da construção dos processos referenciais na compreensão dos sentidos textuais.

Partimos do pressuposto de que os postulados preconizados pela proposta teórica da referenciação, sob a perspectiva sociocognitiva, podem fornecer procedimentos metodológico-pedagógicos exequíveis para o processo de ensino-aprendizagem de leitura na educação básica, de modo que as atividades pedagógicas propostas não podem ficar restritas a fazer com que os estudantes identifiquem os recursos coesivos, sem levar em consideração os elementos sociocognitivos e discursivos que contribuem para a produção dos sentidos dos textos.

Assim sendo, constatamos que os aprendizes compreenderam o foco da atividade proposta, que era incitar a sua percepção sobre o fato de que um referente é introduzido e, posteriormente, pode passar por sucessivas recategorizações no decurso da compreensão textual a partir da integração das várias pistas cotextuais, na medida em que, como esclarecem Cavalcante, Custódio Filho e Brito (2014), uma representação proposta para um objeto de discurso não decorre, unicamente, das expressões referenciais utilizadas para designá-lo.

Com as observações feitas, enfatizamos que os pressupostos teórico-metodológicos da Linguística Textual podem colaborar de modo efetivo com os professores da educação básica no que diz respeito à produção de atividades de compreensão textual e na sua prática pedagógica de interação em sala de aula com os estudantes.

Concluímos, finalmente, que é fundamental o professor trabalhar atividades de compreensão textual que busquem estimular a participação efetiva do leitor na produção dos sentidos, para incitar nos alunos a reflexão sobre os usos discursivos. Consideramos, assim, que o texto trabalhado e a atividade de compreensão textual produzida e aplicada instigaram os discentes a participar, pois eles se envolveram bastante com a história narrada. Essa constatação à qual chegamos confirma o que preconizam os PCN (BRASIL, 1998) e a BNCC (BRASIL, 2018), ao enfatizarem que a atividade de 
leitura deve potencializar a construção de sentidos dos textos por parte do leitor.

\section{Referências}

BRASIL. Ministério da Educação. Base nacional comum curricular: educação é a base. Brasília: MEC, 2018. Disponível em: <http://portal.mec. gov.br/index.php?option=com_docman\&vie$\mathrm{W}=$ download \&alias $=79601$-anexo-texto-bncc -reexportado-pdf-2\&category_slug=dezembro2017-pdf\&Itemid=30192 >. Acesso em: 29 abr. 2020.

BRASIL. Ministério da Educação. Secretaria de Educação Fundamental. Parâmetros Curriculares Nacionais: 3ำ e 4ํㅡㄹ ciclos: língua portuguesa. Brasília: MEC/SEF, 1998. Disponível em: <http://portal.mec.gov.br/seb/arquivos/ pdf/portugues.pdf>. Acesso em: 29 abr. 2020.

CAVALCANTE, M. M. et al. Coerência e referenciação. In: MARQUESI, S. C.; PAULIUKONIS, A. L.; ELIAS, V. M. (Orgs.). Linguística textual e ensino. São Paulo: Contexto, 2017, p. 129-146.

CAVALCANTE, M. M.; BRITO, M. A. P. O caráter naturalmente recategorizador das anáforas. In: AQUINO, Z. G. O.; GONÇALVES-SEGUNDO, P. R. (Orgs.). Estudos do discurso: caminhos e tendências. São Paulo: Paulistana, 2016, p. 119133.

CAVALCANTE, M. M.; CUSTÓDIO FILHO, V.; BRITO, M. A. P. Coerência, referenciação e ensino. São Paulo: Cortez, 2014.

CAVALCANTE, M. M.. Referenciação: sobre coisas ditas e não ditas. Fortaleza: UFC, 2011.

CUSTÓDIO FILHO, V. Análise da referenciação por meio de traços de significação. In: FIGUEIREDO, M. F. et al (Org.). Textos: sentidos, leituras e circulação. Franca, SP: Unifran, 2014, p. 199-224.
CUSTÓDIO FILHO, V. Múltiplos fatores, distintas interações: esmiuçando o caráter heterogêneo da referenciação. 2011. 329 f. Tese (Doutorado em Linguística) - Programa de PósGraduação em Linguística, Universidade Federal do Ceará, Fortaleza, 2011.

KOCH, I. G. V.; ELIAS, V. M. Ler e compreender: os sentidos do texto. 3. ed. São Paulo: Contexto, 2018.

KOCH, I. G. V. Introdução à Linguística Textual: trajetória e grandes temas. 2. ed. São Paulo: Contexto, 2017.

MONDADA, L.; DUBOIS, D. A construção dos objetos de discurso e categorização: uma abordagem dos processos de referenciação. Tradução de Mônica Magalhães Cavalcante. In: CAVALCANTE, M. M.; BIASI-RODRIGUES, B.; CIULLA, A. (Orgs.). Referenciação. São Paulo: Contexto, 2003, p. 17-52.

SANTOS, L. W.; COLAMARCO, M. Referenciação e ensino: panorama teórico e sugestões de abordagem de leitura. Gragoatá, Rio de Janeiro, v. 19, n. 36, p. 43-62, 2014. Disponível em: <https://periodicos.uff.br/gragoata/article/ view/32983>. Acesso em: 20 abr. 2020.

SOUZA, R. A. S. de. Processos referenciais em textos de alunos do 9o ano do ensino fundamental: uma proposta de interação entre alunos-produtores e professores-leitores. 2015. 196 f. Dissertação (Mestrado Profissional em Letras) - Programa de Mestrado Profissional em Letras, Universidade Estadual do Ceará, Fortaleza, 2015. Disponível em: <http://www. uece.br/profletras/dmdocuments/Renata $\% 20$ Abreu\%20Siv\%C3\%A9rio\%20de\%20Souza Disserta\%C3\%A7\%C3\%A3o.pdf>. Acesso em: 15 abr. 2020.

Recebido em: 30/03/2021 Aprovado em: 29/08/2021 